\title{
A CLÍNICA DASEINSANALÍTICA: CONSIDERAÇÕES PRELIMINARES
}

\author{
The Daseinsanalitical Clinic: Preliminary Considerations
}

La Clínica Daseinsanalítica: Consideraciones Preliminares

Ana Maria Lopez Calvo de Feijoo

\begin{abstract}
Resumo: Neste artigo, serão apresentados dois pilares da história da daseinsanálise para então discutirmos elementos inscritos em uma daseinsanálise atual. O primeiro pilar consiste na proposta de Ludwig Binswanger, que vai tomar como referência as noções de projeto e cuidado, considerando a questão da existência humana como ser-aí em seu caráter de indeterminação, finitude e poder-ser. O segundo pilar são as tonalidades afetivas da angústia e do tédio, este considerado por Boss como a tonalidade afetiva que abarca o homem em um mundo onde o que predomina é o horizonte da técnica. Estas questões foram tratadas ontologicamente por Martin Heidegger e consideradas em uma aproximação com a psiquiatria, primeiramente por Binswanger e tendo continuidade com Boss. Por fim serão apresentados alguns elementos imprescindíveis a uma elaboração mais recente da daseinsanálise.
\end{abstract}

Palavras-chave: Daseinsanálise; Projeto; Cuidado; Angústia; Tédio.

Abstract: This article presents two pillars essential for a daseinsanalyse perspective, which current elements are focused on this study. The first pillar, the Binswanger's daseinsanalyse, takes its references from the notions of project and care (Sorge), considering the question of being as a Dasein in its character of indetermination, finitude and could be. The second pillar refers to angst and tedium, the latter, considered by Boss as the affectivite tone wich embraces the man into a world where the thecnology horizon is a must. All these issues were ontologically examined by Martin Heidegger and considered in a psychiatric perspective, first, by Binswanger, and than, by M. Boss. Finally, some important elements for the recent daseinsanalyse elaboration will be submitted.

Keywords: Daseinsanalyse; Project; Care; Angst; Tedium.

Resumen: En este artículo se presentarán dos pilares en una perspectiva de daseinsanalítica. La primera es la propuesta de la daseinsanálisis de Binswanger para referirse a los conceptos de proyecto y cuidado, considerando la cuestión de la existencia humana como Dasein en su carácter de indeterminación, finitud y poder ser. Y, el segundo pilar son el aburrimiento y el malestar afectivo de matices, esto considerado por Medard Boss como el tono afectivo que afecta al ser humano en un mundo donde lo que predomina es el horizonte de la técnica. Estas cuestiones han sido así tratadas ontológicamente por Martin Heidegger y considerado en primer lugar, en psiquiatría y psicoterapia por Ludwing Binswanger y tuvo continuidad con Medard Boss. Finalmente, serán presentados algunos elementos imprescindibles para una elaboración más recientes en daseinsanálise.

Palabras-clave: Daseinsanálisis; Proyecto; Cuidado; Angustia; Aburrimiento.

\section{Introdução}

A clínica psicológica de que trataremos aqui recebeu, em 1941, a designação de Daseinsanálise, em um congresso de psicoterapia, realizado em Paris. Foi Binswanger quem assim denominou esta modalidade clínica, inspirado nas noções de projeto e cuidado que se encontram discutidas em Ser e Tempo (Heidegger, 1927/1989). A denominação de Daseinsanálise foi mantida por Medard Boss que, no desenvolvimento de sua clínica, enfatizou as noções de tonalidades afetivas, principalmente, o tédio. Tanto Binswanger quanto Boss buscaram em Heidegger elementos para a elaboração de suas daseinsanálises. O filósofo da daseinsanálise - Heidegger - sustenta em sua filosofia a possibilidade de elaboração de uma clínica.
Primeiramente, é o próprio filósofo que se refere à analítica do Dasein como a análise ontológica das estruturas da existência humana e, em um segundo momento, em seus Seminários de Zollikon (Heidegger, 1987/2001) aponta para a possibilidade de uma clínica psicológica com bases na fenomenologia hermenêutica.

Os psiquiatras Ludwig Binswanger e Medard Boss, inspirados no filósofo, vão denominar de daseinsanálise o exercício desta analítica em uma perspectiva ôntica, ou seja, na relação com problemas existenciais. O primeiro vai dialogar mais atentamente com a noção de tempo tal como desenvolvida por Heidegger. Já o segundo toma para sua clínica a noção de espaço, como atmosfera do horizonte histórico que dá o tom - afetos da convivência - com o qual nos afinamos. 


\section{O Percurso de Binswanger na Daseinsanálise}

Binswanger (1947/1971) escreve um capítulo que versa sobre psicoterapia, iniciando-o com uma pergunta que ele mesmo dirigiu aos participantes de um congresso que acontecia na Suíça: "O que vocês esperam, em primeiro lugar, de uma conferência sobre psicoterapia?”. Os jovens estudantes responderam sem hesitação: "Que você nos explique como a psicoterapia pode agir" (p.119). Em 2010, ao apresentar a clínica psicológica em uma perspectiva daseinsanalítica em uma grande platéia composta por estudantes de psicologia, professores universitários e psicólogos, a mesma questão foi incessantemente encaminhada de modo que se tornava claro que os participantes, tal qual a platéia de Binswanger, queriam saber do como fazer para obter resultados e eficácia no procedimento clínico.

É compreensível que no horizonte histórico onde predomina a técnica, os profissionais pensem a partir das orientações da técnica e perguntem qual é o remédio, qual é a palavra, como agir para encontrar este ou aquele resultado. Binswanger (1947/1971, p. 119) responde a sua platéia da seguinte forma: "[...] mas somente pelo discurso humano, pelas palavras e por todos os outros meios pelos quais o homem pode entrar em contato com o homem e agir sobre si mesmo.” Com isto, Binswanger quis dizer que a clínica psicológica não deve ser regida por pressupostos teóricos, com orientações de como fazer a partir do controle e precisão na aplicação do método. Este trecho traz algumas questões que merecem um esclarecimento mais detalhado. Cabe a pergunta: "Quem foi Binswanger?", uma vez que por diferentes motivos, ele e suas obras ficaram quase que em anonimato. Suas obras em alemão, com raríssimas exceções, foram traduzidas para outro idioma. E, ainda, por ter se afastado da daseinsanálise, esta modalidade clínica ficou muito mais vinculada a outro psiquiatra, também suíço, Medard Boss, do que ao seu próprio criador. Cabem ainda outras perguntas: "Qual foi o projeto de clínica psicológica elaborado por Binswanger?" e "É possível uma atuação clínica que não tenha um método, que conduza a resultados?"

Sobre a pergunta de quem foi Binswanger, cabe então ater-se ao seu percurso na análise existencial. Ludwig Binswanger estudou com Heidegger. Aprofundando-se no detalhamento de Ser e Tempo, encontrou duas referências que vão fundamentar a sua clínica: a noção de projeto e de cuidado. Binswanger, também estudioso das obras fenomenológicas de Husserl, toma para a psiquiatria a ideia de ir às coisas mesmas e se interessa pela estrutura da intencionalidade. Passa a orientar sua investigação psiquiátrica, por via da compreensão e busca nas determinações existenciais, no próprio ato de existir, as condições de possibilidades do ser enfermo. Passa, então, a descrever diversos casos clínicos, principalmente com diagnóstico de esquizofrenia, como o conhecido caso Ellen West.
Com seus estudos em Heidegger e Husserl, concluiu que a psiquiatria médica encontrava-se muito preocupada com a estatística e suas referências de normatividade. E com estas referências, a psicopatologia elaborava as categorias de diagnóstico, com ênfase nos determinantes biológicos das enfermidades psíquicas. Desta forma, a ciência médica solidificava seus dogmas. Binswanger inquietava-se com a insuficiência destes estudos. Ele considerava que a psiquiatria esquecia-se da existência propriamente dita, uma vez que sua visada dirigia-se aos critérios endógenos ao existir. No dia 22 de setembro de 1950, esse psiquiatra apresentou no primeiro congresso internacional de psiquiatria em Paris, uma conferência intitulada $A$ Daseinsanalyse, que na tradução francesa recebeu a denominação de Analyse de la présence. Em uma versão portuguesa, tem-se adotado a mesma terminologia alemã Daseinsanalyse ou então daseinsanálise.

Ao apresentar a Daseinsanalyse aos participantes do Congresso ocorrido em Paris, o psiquiatra comunicou um novo método de investigação em psiquiatria e psicoterapia. O termo foi adotado finalmente por Binswanger em 1941 para substituir a denominação "Análise Existencial”. Esta última expressão foi utilizada na época pela maioria dos psicólogos e psiquiatras que se opunham ao determinismo e ao instrumentalismo das teorias científiconaturais. A utilização do termo em tamanha amplitude acabou por demarcar muito mais um espaço de oposição às psicologias científicas ou psicodinâmicas do que propriamente por caracterizar uma identidade positiva. Com Binswanger, a daseinsanálise passa a designar uma abordagem em psicologia e psiquiatria que mantém um diálogo rigoroso com as descobertas alcançadas em Ser e tempo. A partir desta aliança, passamos, então, a compreender o homem não mais como resultado de um determinismo, nem mesmo como forças e complexos psíquicos que agem de modo oculto nas expressões aparentes do homem.

Binswanger constrói o seu projeto de daseinsanálise com duas referências ampla e profundamente discutidas por Heidegger em Ser e tempo. São elas: a noção de projeto e de cuidado. Com a noção de projeto, Binswanger encontra a saída para a insuficiência do modelo natural, estatístico, normativo, determinístico que transcendem toda e qualquer existência. A noção de projeto em Heidegger aponta para que as estruturas ontológicas dos modos de ser do homem sejam investigadas em sua temporalidade já que a cotidianidade desentranha-se como modo de temporalidade. Diz Heidegger (1927/1989, p. 14): "o projeto de um sentido de ser em geral só pode se realizar no horizonte do tempo". Projeto diz respeito ao sentido temporal da projeção da existência. A vida é um projeto já que se parte de um estar lançado, projetando a existência para algumas possibilidades e excluindo outras, porém, sempre desvelando possibilidades. Se a temporalidade constitui-se no sentido ontológico originário do 
ser-aí, então, cuidado deve precisar de "tempo" e, assim, “contar com o 'tempo"”.

A outra noção heideggeriana de extrema importância na construção clínica de Binswanger vai ser o cuidado ou cura (Sorge). Heidegger, em Ser e Tempo, traz a fábula de Higino sobre o cuidado para poder em uma comunicação indireta deixar o impacto do sentido desta estrutura fundamental do Dasein.

Certa vez, atravessando um rio, "Cura” viu um pedaço de terra argilosa: cogitando, tomou um pedaço e começou a lhe dar forma. Enquanto refletia sobre o que criara, interveio Júpiter. Cura pediu-lhe que desse espírito à forma da argila, o que ele fez de bom grado. Como Cura quis então dar seu nome ao que tinha dado forma, Júpiter a proibiu e exigiu que fosse dado o seu nome. Enquanto "Cura” e Júpiter disputavam o nome, surgiu também a terra (tellus) querendo dar o seu nome, uma vez que havia fornecido um pedaço de seu corpo. Os disputantes tomaram Saturno como arbítrio. Saturno pronunciou a seguinte decisão, aparentemente equitativa: “Tu, Júpiter, por teres dado o espírito, deves receber na morte o espírito e tu, Terra, por teres dado o corpo, deves receber o corpo. Como, porém, foi a Cura quem primeiro o formou, ele deve pertencer à Cura enquanto viver. Como, no entanto, sobre o nome há disputa, ele deve se chamar "homo", pois foi feito de húmus (terra) (1927/1989, p. 263-264).

O cuidado não se refere a um determinado modo de relação, e sim à condição de ser aberto às possibilidades de relação nas suas diferentes modalidades. Heidegger vai proceder à análise das estruturas do ser-aí, tomando o cuidado, sorge, em um lugar central e determinado na estrutura ontológica, constituindo-se em uma confirmação pré-ontológica da analítica existencial. O homem em uma relação cooriginária com o mundo é cuidado com os entes disponíveis, com os outros e consigo mesmo. O ser do ser-aí, como cuidado, fala da unidade do todo existencial do ser-aí, que se põe diante de si mesmo e se abre para si em seu estar lançado, portanto, não se fecha, a sua constituição é abertura.

O ser do estar-aí é o cuidado, que traz um duplo sentido. $\mathrm{O}$ cuidado que entrega o estar-aí às possibilidades mais próprias: projeto ao mesmo tempo em que entrega o homem ao mundo - estar-lançado. A noção de projeto abre o campo existencial, que é o nosso, às possibilidades. Só nos é possível o que o campo existencial torna possível.

Binswanger considerou que à estrutura ontológica constitutiva do Dasein, “cuidado" (sorge), deveria se acrescentar a noção de amor, não deixando dúvida quanto ao fato de ter entendido o cuidado como uma estrutura ôntica. Assim, ele manteve em última instância a ideia de uma subjetividade fechada em si mesma, dotada da possi- bilidade de se relacionar eticamente com os outros a partir da empatia. Com isso, Heidegger acusa Binswanger de manter uma ênfase em psicologia que se aproximava mais da posição da filosofia da subjetividade (Boss \& Condrau, 1976). O psiquiatra, reconhecendo que mantinha o pressuposto da subjetividade passa, então, a nomear a sua abordagem de "Fenomenologia Antropológica" e a retomar uma proximidade maior com relação a Husserl.

Em conclusão, Binswanger busca a ontologia de Heidegger por não estar de acordo com o determinismo e a causalidade, bem como com as suposições de forças ocultas determinantes do comportamento. Parte para uma análise do Dasein, considerando as estruturas existenciais de espacialidade, temporalidade, corporalidade, ser-com, humor e o ser-para-a-morte. Nestes aspectos, se apropria das reflexões de Heidegger. Por outro lado, continuou ligado à psicanálise nas suas interpretações psicodinâmicas. E ao tratar do amor como um originário, mais fundante que o "cuidado", recai em uma perspectiva ôntica, como afirma Heidegger (1987/2001) em correspondência a Medard Boss, datada de 30 de novembro de 1965: "A Daseinsanálise de Binswanger de acordo com seu caráter fundamental é uma interpretação ôntica, isto é, uma interpretação existencial do respectivo Dasein factual".

\section{O Projeto de Daseinsanálise de Medard Boss}

A daseinsanálise voltou a ser discutida nos encontros regulares de Medard Boss com Heidegger e outros médicos e psicoterapeutas, publicados com o título de Seminários de Zollikon (Heidegger, 1987/2001). Nesses seminários, que aconteceram de 1959 a 1969, abriramse outras possibilidades de discussão da possibilidade de uma clínica psicológica a partir da fenomenologia hermenêutica de Heidegger.

Medard Boss (1988), no prefácio de Angústia, culpa e libertação, reconhece que deve a Heidegger toda a sua formação filosófica. Confessa que, como médico, jamais poderia reconstruir a sua prática terapêutica. Neste livro, demonstra a sua fundamentação daseinsanalítica por meio de três trabalhos que foram elaborados durante dez anos e, nesta publicação, compilados: angústia vital, sentimento de culpa e libertação psicoterápica. Destaca algumas questões que considera imprescindíveis para se pensar a clínica a partir dos pressupostos heideggerianos: a inseparabilidade do orgânico e do psíquico, a angústia e a culpa como fatores de suma importância no âmbito dos psiquicamente doentes e, por fim, o caminho para a libertação. Além destas, Boss pensou muitas outras questões em psicologia, tais como o ser-doente, os distúrbios psíquicos e a psicossomática. Para o exercício clínico trouxe como contribuição a interpretação dos sonhos a partir de uma tematização de sentido que aquele que sonha atribui ao sonhado. 
A daseinsanálise de Boss toma como questões fundamentais as tonalidades afetivas que foram mais detidamente desenvolvidas por Heidegger a partir de 1930, o denominado Heidegger tardio. Para Heidegger (1929/ 2006) as tonalidades afetivas são determinantes do modo como experimentamos o mundo e, portanto, para o modo que nos encontramos em um espaço compartilhado. Enfim, são afinações da convivência que não só acompanham nossos atos como também determinam à temporalidade que acompanha as nossas ações.

A angústia, anúncio da negatividade da existência, é uma tonalidade afetiva fundamental que, ao descerrar mundo, rompe com as sedimentações do mundo fático, lança o horizonte de sentido, mundo, em uma insignificância radical. Deste modo, tudo cai em uma total indiferença e em um radical esvaziamento. E é nesta situação limite, com o romper das prescrições do mundo, que ocorre um despertar para o espaço de realização do ser-aí, ou seja, abre-se o seu poder-ser. A angústia, ao apontar para a negatividade originária da existência, coloca em jogo a compreensão da finitude que abre o caráter de nada da existência, do ente ontologicamente incompleto e indeterminado, desvelando o poder do mundo sobre nós. A angústia mobiliza duas situações: um despertar para um sentido e, ao mesmo tempo, a tentativa de não deixar que desperte. A angústia conclama o ser-aí a apropriar-se da sua existência mais própria. Ela emerge como um mobilizador existencial que, imediatamente, abre duas possibilidades: na tentativa de livrar-se da angústia, o ser-aí ou bem retoma a tutela do mundo e volta àquilo que lhe é familiar, ou bem se concretiza no poder ser, singulariza-se, o que consiste na perda, nem que seja por um instante, da tutela do mundo.

O tédio, também tonalidade afetiva fundamental e, portanto, descerradora de mundo, desperta em nós uma total suspensão do horizonte do existir, esvaziamento radical do tempo, que ao acontecer todas as possibilidades desaparecem. Cai sobre a existência uma radical indiferença, um verdadeiro tanto faz, como tão bem descrita por Herman Merwille (2008) em Bartleby, com a sua repetição incessante de "prefiro não fazer". Expressão que revela a total indiferença e desinteresse pelo mundo.

O tédio profundo, tonalidade afetiva que nasce do fato de tornarmo-nos desinteressantes para nós mesmos, não é algo externo, mas ficamos entediados: tudo nos diz muito pouco ou nada. A rotina, a repetição, traz a ausência de sentido e ao sentir que nada tem sentido, o tédio alerta para o insuportável do cotidiano, do familiar, do ser obrigado a viver. Porém, tudo é igual, tudo é o mesmo, igual a nada, trata-se da absoluta indiferença. Tonalidade afetiva que denuncia a totalidade inabarcável que nos assalta e nos afunda. E, nesse horizonte dessa lenta demora, nada tem sentido. E é desse nada que é tudo, que se desiste. Para Heidegger, o tédio profundo mobiliza duas situações: um despertar para um sentido e ao mesmo tempo a tentativa de não deixar que desperte. Na tonalidade afetiva fundamental do tédio transparece o mais próprio do ser-aí: ser-para-a-morte. Na disposição do tédio acede sempre a transparência da situação do homem que, em última estância, é finita e transitória.

Uma questão proposta por Heidegger em Os conceitos fundamentais da metafísica (1929/2006) merece ser pensada no interior de uma perspectiva daseinsanalítica: o que fazer frente à mobilização incitada pelo tédio como à angústia frente à antecipação do ser-para-a-morte? Heidegger aposta na não resistência através da distração ou do exacerbamento de ocupações, mas, pelo contrário, deixá-lo ecoar. Diz o filósofo:

Mas como devemos abrir espaço para este tédio inicialmente inessencial e inapreensível? Somente através do fato de não estarmos contra ele, mas de nos aproximarmos dele e de deixarmos que ele nos diga o que quer afinal, o que passa com ele afinal (Heidegger, 1929/2006, p. 99).

Trata-se justamente da postura que o analista em um diálogo clínico deve tomar frente à inquietação daquele que na angústia e no tédio o procura.

Medard Boss apresenta a Daseinsanálise como proposta psicoterapêutica em que os fenômenos do existir possam mostrar-se a partir de si mesmos, afastando-se de um psicologismo. Considera em sua proposta a atmosfera do tédio em nosso horizonte histórico, apontando que, se na época de Freud as questões psíquicas se atrelavam à sexualidade, em nossa época a neurose do tédio é a situação que abarca a nossa existência. O tédio como expressão de um mundo, onde os sentidos encontram-se sedimentados nas determinações técnicas, ocorre o total esvaziamento e desenraizamento do homem com o seu sentido mais originário: a existência.

Boss ainda mantém em seus textos uma discussão sobre a diferença entre os pensamentos de Freud e de Heidegger e, na sua prática psicoterapêutica, mantém alguns ensinamentos psicanalíticos. Admite o divã, as associações livres e, também, a transferência. (May, 1974). Ao mesmo tempo em que faz uma crítica severa aos conceitos psicanalíticos, redefine-os em uma perspectiva existencial. Assim o faz, por exemplo, com relação à transferência. Em Freud, o neurótico transfere a relação e os sentimentos que se dirigiam a seu pai ou sua mãe para seu marido ou sua mulher, ou ainda para seu analista. Aqui os sentimentos estão reprimidos inconscientemente. Para Boss, a pessoa se encontra limitada e restrita em suas possibilidades. Portanto, percebe o analista ou o cônjuge com a mesma limitação com que olhava seu pai ou sua mãe. Não dispondo de novas possibilidades de relação, mantém o mesmo padrão de sua infância

O mesmo ocorre com o conceito de resistência, que em Freud é definida como tudo o que, nos atos e palavras do analisando, se opõe ao acesso deste ao seu inconsciente. Freud concebeu a repressão em função da moralidade 
burguesa, como a necessidade do cliente em manter uma imagem aceitável de si mesmo e, por conseguinte, reprimir os pensamentos, desejos e outras formas de expressão, inaceitáveis dentro de um código moral burguês.

Boss, a partir da perspectiva psicanalítica, diz que a resistência consiste na reação de ação ou repulsa do cliente frente às suas possibilidades. Interessa investigar o que impede o cliente frente às suas possibilidades. Para que ocorra a repressão, primeiramente, o indivíduo tem que aceitar ou rejeitar, isto é, dispor de liberdade para decidir. A repressão implica a perda da consciência da liberdade. Sendo assim, reprimir e não reprimir a liberdade são duas possibilidades. A repressão é uma forma livre de utilizar as possibilidades. É uma opção livre frente a alternativas. Resistência constitui-se no excesso da tendência do indivíduo a refugiar-se no Mitwelt, refugiarse na humanidade abstrata, no anonimato, renunciar às suas possibilidades peculiares, únicas e originais, cair no "conformismo social".

Boss importa-se com a estrutura da existência humana. Freud importa-se com o inconsciente. Ambos tentam tirar a psicologia do reino carismático e aleatório e aceitála como campo de exploração e compreensão e, assim, constituí-la em uma disciplina que, até certo ponto, pode ser ensinada.

Embora Heidegger tenha dado o seu aval à proposta da daseinsanálise de Boss, esta ainda guarda no seu interior alguns vestígios de uma psicodinâmica, tal como pode ser observado ao se referir à angústia e à culpa como sendo os fundamentos básicos para livrar os pacientes com sintomas psiconeuróticos de seus aprisionamentos (Boss, 1988, p. 42). Em outro trecho, Boss afirma que a principal meta da psicoterapia é conduzir os pacientes para a capacidade de amar e confiar (Boss, 1988, p. 43). Estes, dentre outros trechos, colocam em dúvida se a clínica em Boss ainda tem ou não pretensões interventoras, que pretendem levar o analisando para um objetivo com ênfase valorativa.

Seja pela divulgação restrita, seja por ainda manter elementos da psicologia humanista e psicodinâmica, a daseinsanálise não foi incluída no contexto da psicologia de forma ampla. Mantendo-se apenas em grupos muito restritos, não chegou a ser conhecida nem devidamente estudada no âmbito da psicologia. Pouco ainda se tem feito em termos de divulgar, ampliar e aprofundar os fundamentos de uma daseinsanálise clínica. Há estudos esparsos que apontam para algumas considerações da possibilidade de uma clínica psicológica daseinsanalítica, mas que ainda carecem de um aprofundamento e detalhamento mais apurado. Talvez estudos mais aprofundados e detalhados acerca da fenomenologia-hermenêutica oferecessem consistência e abrangência ao exercício clínico, podendo, assim, levar efetivamente o exercício da clínica daseinsanalítica à formação acadêmica do psicólogo.

\section{Estudos Atuais em Daseinsanálise}

Estudos atuais vêm se desenvolvendo em daseinsanálise e, aqui no Brasil, pelo menos dois grupos vem estudando a esta perspectiva na clínica psicológica: a Associação Brasileira de Daseinsanalyse, em São Paulo e o Instituto de Psicologia Fenomenológico-Existencial, no Rio de Janeiro. Esses estudos engendram-se em uma saída epistêmica e ontológica indo até seus fundamentos: a fenomenologia-hermenêutica de Heidegger. Para prosseguirmos na discussão de uma clínica daseinsanalítica, é necessário que se esclareçam os elementos preliminares, que muito contribuíram para a originalidade da obra heideggeriana e suas repercussões na clínica. Podemos encontrar na proposta fenomenológica, inaugurada por Husserl e levada adiante por Heidegger, o eu não mais dicotomizado do mundo, mas pensado antes como um fluxo de vivências intencionais fundadas na imanência de uma consciência já sempre projetada para além de si (Husserl) ou como um campo existencial de sentido e significados compartilhados assentado na temporalidade do ser-aí (Heidegger). Vejamos melhor o que isso importa para a possibilidade mesma da daseinsanálise.

Sem dúvida, a clínica daseinsanalítica tomará a analítica do Dasein, tal como elaborada por Heidegger, para então proceder a uma daseinsanálise que consista no exercício ôntico da analítica. Ao se tomar o eu como abertura, ausência dinâmica em jogo com o mundo, e ao se assumir a fenomenologia hermenêutica como atitude interpretativa frente ao fenômeno, passa-se a estabelecer uma outra articulação para a psicologia a partir da fenomenologia e da hermenêutica. Inaugura-se, então, uma outra atuação clínica, ou seja, um novo comportamento clínico que, inspirado em Heidegger, recebe a denominação de daseinsanálise.

Para se proceder a uma clínica fenomenológica, parte-se do pressuposto de que toda e qualquer teoria acerca da existência humana deve ser suspensa para que, assim, seja possível se aproximar do fenômeno (no caso, a questão trazida pelo paciente), atendo-se a todo o detalhamento de como se dá o acontecimento em questão. Em uma postura hermenêutica, consideramos os horizontes hermenêuticos que estarão sempre presentes na situação clínica, e o que de fato se interpreta são os encontros de horizontes, que consistem precisamente no que se fala e se escuta. Este choque de horizontes é o horizonte mesmo de apreciação do que acontece no encontro clínico, ou seja, da aparição da questão (fenômeno).

A tarefa de uma clínica daseinsanalítica consiste, primeiramente, no fato de que o analisando deve ser o mais preciso possível em suas descrições e o analista deve, incessantemente, atentar para as interpretações do paciente, tentando, assim, alcançar uma compreensão daquilo que está em jogo na descrição do analisando. Em continuidade a esta tarefa, precisamos, também, quebrar ou destruir 
os comportamentos ontológicos presentes nas descrições do analisando. Esta clínica consiste em abrir um espaço para que o outro se conquiste em sua alteridade. Abrir espaço, sem conduzir; traduzir, sem mapear um caminho que leve a algo como uma conscientização.

Em uma visada hermenêutico-fenomenológica, o problema consiste no aprisionamento em nossas histórias, nos modos como vamos sufocando não o problema que temos, mas o problema que nós somos. A tarefa de uma clínica fenomenológica consiste em quebrar o aglomerado de vivências que se dão na mistura de campos intencionais e que provocam a quebra do fluxo do tempo do eu. E, assim, possibilitar que o instante e lugar do acontecimento se deem. Abrimos espaço para que o analisando possa aperceber-se das suas vivências próprias e a colocar-se diante do campo intencional em que o fenômeno se constituiu. Enfim, em uma narrativa fenomenológica, importa o modo como uma hermenêutica-fenomenológica vai se dando, em um horizonte fundido, abrindo espaço para que o analisando apareça para si mesmo

O analista em uma atitude fenomenológica, antinatural, não diagnostica nem interfere; mas posiciona de modo que aquele que está dizendo alguma coisa ganhe voz em si mesmo. No interior da interpretação clínica, o analista coloca em suspensão seus pressupostos e, assim, deixa que as interpretações de sentido surjam por aquele que se reconhece estranho a si mesmo, apenas articulando quais são os pressupostos que irá combater, bem como o modo cuidadoso com que vai fazer o combate. $\mathrm{O}$ analista, atendo-se a todo o detalhamento de como se dá o acontecimento em questão, dará prosseguimento ao desvelamento da estrutura de sentido em jogo nesta situação. E assim solicita e incita a descrição do que vem acontecendo com o analisando. Age desta forma para que a questão apareça, no final das contas, para o próprio que a coloca. Trata-se de fazer emergir o horizonte mais originário da transformação. Para Heidegger, é por meio das tonalidades afetivas fundamentais que aparece a crise do projeto impessoal, da qual nasce a singularização.

Um analista, no entanto, não deve desprezar os horizontes hermenêuticos que estarão sempre presentes na situação clínica. E o que de fato se interpreta são os encontros de horizontes, que consistem precisamente no que se fala e se escuta, a partir de uma relação intencional. Este choque de horizontes é o horizonte mesmo de aparição do que acontece no encontro clínico, ou seja, da aparição da coisa. Quando o fundir dos horizontes se dá de maneira integral, essa fusão abre o espaço para que o outro apareça para ele mesmo. O que o analisando diz vai ser escutado a partir do horizonte compreensivo do analista, porém o analisando é a orientação, a medida.
Esta clínica se estabelece muito mais em uma negatividade do que propriamente a partir de uma identidade positiva. O ser-aí que, marcado pela nadidade e pela fragilidade ontológica, busca a estabilidade do mundo, que se constitui em um apoio, suporte e tutela. Mas é exatamente esta busca que o coloca na cadência do mundo, esquecendo-se do seu próprio ritmo, acaba obscurecendo o seu caráter de poder ser. São as situações limites que, ao entrarem na articulação do ser-aí e mundo, rompem com os sentidos sedimentados, e o vazio aparece, e no nada padece. A angústia emerge como um mobilizador existencial que, imediatamente, abre duas possibilidades: na tentativa de livrar-se da angústia, o ser-aí ou bem retoma a tutela do mundo e volta àquilo que lhe é familiar, ou bem concretiza-se no poder ser, singulariza-se, o que consiste na perda, nem que seja por um instante, da tutela do mundo.

Acreditamos que a discussão aqui apresentada preste os esclarecimentos oportunos acerca da real possibilidade de se articular uma clínica psicológica a partir da fenomenologia hermenêutica de Heidegger. Ela esclarece, também, que a substancialização do psiquismo não consiste de modo nenhum em uma condição necessária para que a clínica psicológica aconteça, já que não importa a interioridade, mas sim a articulação ser-aí/mundo. E é esse corresponder que se encontra perturbado quando a desarticulação acontece.

Vale ressaltar que toda transformação que se dá, seja o processo clínico bem como o da existência em geral, não acontece pela vontade do analista ou do próprio analisando. Há algo que desencadeia a atmosfera, há algo que realmente mobiliza a transformação que se encontra em um horizonte mais originário, que para Heidegger consiste nas tonalidades afetivas fundamentais: dentre outras a angústia e o tédio.

Com toda a discussão aqui apresentada, pudemos constatar que a clínica psicológica pode acontecer prescindindo de teorias e pressupostos. E também que é possível uma atuação clínica por meio de uma atitude fenomenológica, postura antinatural, que acontece apenas na manutenção de espaços de abertura para que novas possibilidades apareçam.

\section{Referências}

Binswanger. L. (1971). Introduction à l'analyse existentelle. Paris: Les Editions de Minuit. (Original publicado em 1947).

Boss. M. (1988). Angústia, culpa e libertação. São Paulo: Livraria Duas Cidades.

Boss, M. \& Condrau, J. (1976). Análise existencial - daseinsanalyse: como a daseinsanalyse entrou na psiquiatria. Revista Daseinsanalyse, 2, 5-23.

Heidegger. M. (1989) Ser y tiempo. Madrid: Editorial Gredos. (Original publicado em 1927). 
Heidegger. M. (2006) Os conceitos fundamentais da metafísica: mundo, finitude e solidão. Rio de Janeiro: Forense Universitária. (Original publicado em 1929).

Heidegger. M. (2001) Seminários de Zollikon. Petrópolis, RJ: Vozes. (Original publicado em 1987).

May, R. (1974). Psicologia existencial. Porto Alegre: Globo.

Merwille, H. (2008). Bartleby: o escriturário. Porto Alegre: L\&M.
Ana Maria Lopez Calvo de Feijo - Doutora em Psicologia, ProfessorAdjunto da Graduação e do Programa de Pós-Graduação em Psicologia Social da Universidade do Estado do Rio de Janeiro. Endereço Institucional: Universidade do Estado do Rio de Janeiro, Departamento de Psicologia Clínica, Instituto de Psicologia. Rua São Francisco Xavier, $n^{\circ} 524$ (Maracanã). CEP: 20.550-013 - Rio de Janeiro-RJ. Email: ana.maria.feijoo@gmail.com.br

Recebido em 31.01.11

Aceito em 15.05.11 